\title{
EDITORIAL
}

\section{Postgraduate Medical Education : An Overview}

At Dhaka Post graduate Medical education was introduced in 1940's with establishment of School of tropical Medicine and Hygiene. This offered Diploma in Tropical Medicine of university of London. In 1961 Dhaka University Ordinance for Post Graduate courses were adopted. Courses in both Basic Medical science and Clinical Science were approved under Faculty of Medicine. ${ }^{1}$ The College of Physicians and Surgeons Pakistan was established in 1962. In 1965 Institute of Post Graduate Medicine and Research started functioning. In 1973 Faculty of Post Graduate Medical science and research started as a separate entity. National Professor Nurul Islam was the first Dean. Government of the Peoples' Republic of Bangladesh constituted an ad hoc committee of the College of Physicians and Surgeons of Bangladesh with Professor K S Haque as the President in 1972. ${ }^{2}$ All fellows of the College of Physicians and Surgeons of Pakistan who hailed from Bangladesh were admitted as the founder fellows. With great endeavors and untiring efforts, these people were able to hold the first examination in July 1972. Bangabandhu Sheikh Mujib Medical University is the first and only medical university in Bangladesh, established in $1998 .^{3}$

Though Royal College of Physicians of London was establishment in 1518, it took long time before the concept of postgraduate medical education started to bloom. Postgraduate medical education association was set up in UK in 1911 and Sir William Osler became its President. Osler in a valedictory address at McGill said "The hardest conviction to get into the mind of a beginner is that the education upon which he is engaged is not a college course, not a medical course but a life course, for which the work of a few years under teacher is but a preparation. ${ }^{4}$

Postgraduate medical education is based on adequate undergraduate training. Advanced learning necessarily demands sound understanding of the basics of the specialty. This again depends on the input in the medical colleges. Therefore postgraduate medical education cannot be considered in isolation. Considering the scenario of mushrooming of medical colleges without enough teachers, it is expected that outcome of medical graduates will fall short. But there will be students and institutes out performing and the post graduate program should have the ability pickup those students, otherwise long time \& efforts in training of under qualified doctors may go in vain.

Once decided whom to train, next comes the question of how to do it. Colleges and educational bodies around the world decided on certain issues, like Professionalism, Humanism, skill, knowledge, and making learners ability of self learning and become a lifelong learner. Role of training institutes remains to provide requirements for expected outcome, providing opportunity to learn \& assessing their performance time to time. At the same time degree/ diploma giving authority has to ensure the availability of resources and opportunities to the students of these training institutes by continuous monitoring.

The problems of medical education in a developing economy are many. Since the number of seats for the post graduation courses are very limited compared to the number of students being graduated, the students pay lesser attention on the practical training and more emphasis on the theoretical knowledge to score high in the PG entrance exams and part I exam as a result they are often found deficient in the performance of clinical skills and problem-solving which form the core of clinical competence. ${ }^{8}$ Students fail to acquire the clinical skills, leadership qualities and human resource management to their maximum potential thus affecting the quality of doctors being produced. Assessment system, lack of facilities in the undergraduate program also contributes to this.

This is in sharp contrast to system followed in USA, where students need to pass a practical exam of United States Medical Licensing Examination (USMLE) step 2 Clinical Skills (CS) ${ }^{[5]}$ Thus students need to have effective practical clinical skills before they can get license to practice in USA or to be eligible for admission to residency for higher education. 
Specialist training mostly is in the traditional apprenticeship style rather than an appraisal based approach. Selection of assessment tools is not always governed by modern educational theory. Training in research, ethical issues, concepts of team work, and management is variable. Standards for accreditation are ill defined and not uniformly applied. Some institutes, however, have initiatives to meet these challenges.

The Accreditation Council for Graduate Medical Education (ACGME) in the USA has identified six learning outcomes for postgraduate medical education: patient care, medical knowledge, interpersonal and communication skills, professionalism, practice based learning and improvement, and system based practice.

World Federation for Medical Education (WFME) ${ }^{6}$ recommends a set of global standards in postgraduate medical education structured according to 9 areas: 1 . Mission and Outcomes, 2. Training Process, 3. Assessment of Trainees, 4. Trainees, 5. Staffing, 6. Training Settings and Educational Resources, 7. Evaluation of Training Process, 8. Governance and Administration and 9. Continuous Renewal. Standards are specified for each sub-area using two levels of attainment: Basic standard and Standard for quality development. ?

The Gold Guide: A Guide to Postgraduate Specialty Training in the UK (the "Gold Guide") sets out the arrangements for the introduction of competence based specialty training in the UK. The development of this Guide has been through an iterative process of reflection and discussion using the Postgraduate Deans, Medical Royal Colleges and Faculties, professional associations and the health departments. The Postgraduate Medical Education and Training Board (PMETB) now incorporated within GMC since 2010 in UK, has very clearly described in its recommendations about the training of tomorrows doctor. ${ }^{7}$

While describing postgraduate medical education, $\mathrm{R}$ M Harden ${ }^{8}$ mentioned four themes: the curriculum, the application of learning technologies, assessment of competence, and professionalism in medical education. However, to change our approach to teaching and learning is not easy for we must leave behind part of ourselves and our personal past experiences as trainees and trainers.
Patil ${ }^{9}$ summarises the features of postgraduate training which includes : a progressive syllabus that has both formal and informal elements, a recognized trainer and training unit, proactive supervision, a balance of clinical duties and educational activities, protected time for education, and defined exit outcomes.

Outcome based education: A key trend in postgraduate medical education is a move to a model in which the emphasis has changed to focus on the product and the expected learning outcomes. ${ }^{10}$ In outcome based education, the learning outcomes are clearly specified and decisions about the content of training and how it is organized, the educational strategies to be adopted, the teaching methods, the assessment procedures, and the educational environment are made in the context of the stated learning outcomes. ${ }^{11}$

A unitary approach to medical education: In 1973 Medearis and Kinney ${ }^{12}$ argued convincingly that "medical education must be decompartmentalised and redesigned as a true continuum extending from secondary school through college, medical school, hospital training and postgraduate medical education”. The various stages in the educational program will be integrated with the student and trainee advancing from one stage to the next and the exit learning outcomes of one phase being the entry requirements for the next.

Learning technologies: New learning technologies is a major area where we will see significant changes in postgraduate medical education in future. By using simulators learning is facilitated through the provision of effective feedback ,repetitive practice, a range of difficulty, multiple learning strategies, clinical variation, a controlled learning environment, and individualized learning.

E learning: Harden ${ }^{13}$ highlighted some of the myths associated with e learning and concluded that e learning is not just a passing fad, it is not only about knowledge transfer, on line learning can be effective and efficient, students need not learn in isolation but can be part of an on line community, teachers and trainers have important but different roles, and technology may be queen but pedagogy is king. Khan Academy in USA is an example.

Assessment \& feedback: We will see in the future more performance based assessment including more innovative and greater use of the OSCE. Training should 
include workplace-based assessment. Recommendation of GMC of UK is as follows: (a) systematic observation of clinical practice, (b) direct observational procedure, (c) video, (d) judgments of multiple assessors, (e) consulting with simulated patients, (f) case record review, including OPD letters, (g) case-based discussion, $\mathrm{s}$ (h) oral presentations, (i) $360^{\circ}$ peer assessment , (j) patient feedback surveys, (k) audit projects, (l) critical incident review. Outcomes from assessments must be used to provide feedback to the trainees on the effectiveness of the education and training. ${ }^{14}$

Faculty development: Newer ideas and methods of teaching and learning skill need to be incorporated in the training programs. Though in the advanced countries Department of Medical education is an integral part, it is yet to be in practice in our country. Center for Medical education has been playing some role but that is not adequate. In India National teacher training centers (NTTC) were established in 1974 at many medical colleges \& postgraduate institutes. ${ }^{15}$ NTTC activities includes six- to ten-day programs for medical educators with topics on education objectives, curriculum design, teaching methods, and assessment. Faculty-training courses facilitated the introduction of some innovations in various medical colleges in India and fostered the development of medical education units in other colleges. The USA based Foundation for Advancement of International Medical Education and Research

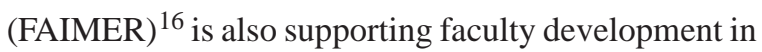
India. Few of our faculties completed their online diploma. All doctors with particular responsibility for training will need to demonstrate evidence that they have acquired the necessary additional skills.

\section{Conclusions:}

Postgraduate Medical education in Bangladesh like many developing countries in Asia \& Africa has its own problems. Lack of coordination among various stakeholders, inadequate number of trainers, poor faculty development program, deficiencies in the undergraduate program, lack of effective curriculum to focus on the structure and outcome of training are few of many.

What is the best way to solve the problems and ensure higher standard of tomorrows specialists? The solution probably lies in following the path of those who have solved their problem. A National commission for postgraduate medical education need to be established with representation from, Medical University, BCPS, Medical \& Dental Council, Ministry of Health and BMA. This commission will review present problems, program of advanced countries and of the developing countries in the region and shall produce a National Guideline. There is no shortcut of structured training program. A National Medical Teachers Training Institute should be established and criterion to become a medical teacher should include training in medical education even if a short one. Like the students, teachers also need to become lifelong learners and that need to be ensured. We are now at the cross road of seeing a growing gap between what is possible educationally and what is delivered. It is clear that we need a new paradigm for postgraduate medical education. Outcome based program with adequate training and faculty development probably does not have any alternative. In delivering this, all stakeholders have a contribution to make and must accept a measure of responsibility for what happens in the future.

It is important that loyalty to the past does not cloud our minds or prevent us from sharing in the joy and satisfaction with what will be possible in the years ahead, if we allow it to happen. The comfort of inertia is not an option, for we need to face up to the annoyance or excitement. $^{8}$

(J Banagladesh Coll Phys Surg 2014; 32: 1-4)

\section{Prof. Humayun Kabir Chowdhury \\ Prof. of Surgery \\ BIRDEM Hospital, Dhaka}

\section{References:}

1. Dhaka University, Available at: http://www.du.ac.bd/faculty/ pgmsr/home.php?pg_name=about_us

2. Bangladesh College of Physicians and Surgeons, available at: http://www.bcpsbd.org/index.php

3. Bangabandhu Sheikh Mujib Medical University, Available at: http://www.bsmmu.edu.bd

4. J. Lister, The history of postgraduate medicine education, Postgrad Med J. 1994 October; 70(828): 728-731

5. Aggarwal S. Comment on medical education, J Postgrad Med 2009;55:318-9.

6 Postgraduate medical education, WFME Global standards, Available at: www.wfme.org 
7 Educating Tomorrows Doctors working group report Available at: http://www.gmc uk.org

8. R M Harden, Trends and the future of postgraduate medical education, Emerg Med J. 2006 October; 23(10): 798-802.

9 Patil N G. The postgraduate curriculum. In: Dent JA, Harden RM, eds. A practical guide for medical teachers. Edinburgh: Elsevier Churchill Livingstone, 2005. 31.

10 Holm H A, Norman GR, van der Vleuten CPM, Newble DI, Postgraduate education. In: International handbook of research in medical education. Dordrecht: Kluwer, 2002. 381413.413.

11 Harden R M, Crosby J R, Davis M H, An introduction to outcome-based education. Med Teach 1999.22(1)7-14.14
12 Medearis D N, Kinney T D. On creating a true continuum of medical education. In: Anlyan WG, Austen WG, Beck JC, et al eds. The future of medical education. Durham NC: Duke University Press, 1973. 133.

13 Harden R M, Myths and e-learning, Med Teach 2002.24(5)469-472.472

14 Postgraduate education and training, General Medical Council UK, Available from: http://www.gmc-uk.org/education/ postgraduate.asp

15 Supe, Avinash; Burdick, William P. Challenges and Issues in Medical Education in India ; Academic Medicine: December 2006 - Volume 81 - Issue 12 - pp 1076-1080

16 Foundation for Advancement of International Medical Education and Research (FEIMER), available from:http:// www.faimer.org/about-board.html 